\title{
Vascular endothelial growth factor contributes to lung vascular hyperpermeability in sepsis-associated acute lung injury
}

\author{
Kengo Tomita ${ }^{1,2} \cdot$ Yuna Saito $^{1,3} \cdot$ Tokiko Suzuki $^{1,4} \cdot$ Samar Imbaby $^{1,5} \cdot$ Kohshi Hattori $^{6} \cdot$ Naoyuki Matsuda $^{7}$. \\ Yuichi Hattori ${ }^{1,8}$
}

Received: 5 July 2020 / Accepted: 13 July 2020 / Published online: 21 July 2020

(C) Springer-Verlag GmbH Germany, part of Springer Nature 2020

\begin{abstract}
Vascular endothelial growth factor (VEGF) is a prime regulator of vascular permeability. Acute lung injury (ALI) is characterized by high-permeability pulmonary edema in addition to refractory hypoxemia and diffuse pulmonary infiltrates. In this study, we examined whether VEGF can be implicated as a pulmonary vascular permeability factor in sepsis-associated ALI. We found that a great increase in lung vascular leak occurred in mice instilled intranasally with lipopolysaccharide (LPS), as assessed by IgM levels in bronchoalveolar lavage fluid. Treatment with the VEGF-neutralizing monoclonal antibody bevacizumab significantly reduced this hyperpermeability response, suggesting active participation of VEGF in non-cardiogenic lung edema associated with LPS-induced ALI. However, this was not solely attributable to excessive levels of intrapulmonary VEGF. Expression levels of VEGF were significantly reduced in lung tissues from mice with both intranasal LPS administration and cecal ligation and puncture (CLP)-induced sepsis, which may stem from decreases in non-endothelial cells-dependent VEGF production in the lungs. In support of this assumption, stimulation with LPS and interferon- $\gamma$ (IFN- $\gamma$ ) significantly increased VEGF in human pulmonary microvascular endothelial cells (HPMECs) at mRNA and protein levels. Furthermore, a significant rise in plasma VEGF levels was observed in CLP-induced septic mice. The increase in VEGF released from HPMECs after LPS/IFN- $\gamma$ challenge was completely blocked by either specific inhibitor of mitogen-activated protein kinase (MAPK) subgroups. Taken together, our results indicate that VEGF can contribute to the development of non-cardiogenic lung edema in sepsis-associated ALI due to increased VEGF secretion from pulmonary vascular endothelial cells through multiple MAPK-dependent pathways.
\end{abstract}

Keywords Acute lung injury $\cdot$ Pulmonary microvascular endothelial cell $\cdot$ Pulmonary vascular permeability $\cdot$ Sepsis $\cdot$ Vascular endothelial growth factor (VEGF)

\section{Introduction}

Sepsis is a potentially life-threatening medical emergency that is caused by the body's extreme response to an infection. The advent of the new definition of sepsis, which has been

Yuichi Hattori

yhattori.med@ivory.plala.or.jp

1 Department of Molecular and Medical Pharmacology, Graduate School of Medicine and Pharmaceutical Sciences, University of Toyama, Toyama 930-0194, Japan

2 Medical Environment Engineering Group, Center for Environmental Engineering, Shimizu Corporation, Institute of Technology, Tokyo 135-0044, Japan

3 Present address: Center for Clinical Training, Juntendo University Urayasu Hospital, Urayasu 279-0021, Japan published recently, prompts a reappraisal of organ dysfunction as the hallmark of sepsis (Singer et al. 2016). Sepsis affects every major organ, including the lung, liver, and kidney, within the body, ultimately leading to the failure of one or more organs. The respiratory system is the most affected organ of

4 J-Pharma Co., Ltd., Yokohama 230-0046, Japan

5 Present address: Department of Clinical Pharmacology, Faculty of Medicine, Suez Canal University, Ismailia 41522, Egypt

6 Department of Anesthesiology and Pain Relief Center, The University of Tokyo Hospital, Tokyo 113-8655, Japan

7 Department of Emergency and Critical Care Medicine, Nagoya University Graduate School of Medicine, Nagoya 466-8550, Japan

8 Advanced Research Promotion Center, Health Sciences University of Hokkaido, Tobetsu 061-0293, Japan 
the body, and lung dysfunction is the first step in the development of multiple organ failure in septic patients. Acute lung injury (ALI) and its most extreme form, acute respiratory distress syndrome (ARDS), are the manifestations of lethal and complex respiratory dysfunction and are characterized by explosive and diffuse pulmonary infiltrates, leading to noncardiogenic alveolar edema and, ultimately, refractory hypoxemia (Tsushima et al. 2009; Matuschak and Lechner 2010).

Vascular endothelial growth factor (VEGF), also known as VEGF-A, is a glycoprotein originally isolated as a tumor cellsecreted vascular permeability factor (Plouet et al. 1989) and, since then, it has long been documented that VEGF serves as the prime regulator of vascular permeability (Bates 2010). While VEGF has been subsequently shown to have additional potent mitogenic and angiogenic properties (Ferrara 2004; Sharma et al., 2011), significant amounts of VEGF are known to exist in the normal human lung without significant mitogenesis or angiogenesis (Barratt et al. 2014). In the normal lung, VEGF may function as a survival factor for epithelial cells and endothelial cells in a paracrine manner (Gerber et al. 1998; Mura et al. 2006; Roberts et al. 2007). In the meanwhile, VEGF may contribute to the development of non-cardiogenic pulmonary edema associated with ALI/ARDS. Lung-targeted overexpression of human $\mathrm{VEGF}_{165}$, using an adenoviral gene vector, has been shown to result in pulmonary edema and increased vascular permeability in mice (Kaner et al. 2000). In addition, it has been revealed that the high ventilation-induced increase in pulmonary microvascular permeability in mice can be attenuated by knockdown of VEGF by short-interfering RNAs (Li et al. 2011). Moreover, pretreatment with adenovirus-encoding soluble VEGF receptor (VEGFR) 1 has been found to prevent ischemia-reperfusion-induced lung injury in rats (Godzich et al. 2006). However, a role of VEGF in pulmonary vascular hyperpermeability accompanied by sepsis-associated ALI is not fully understood.

In the present study, by conducting in vivo and in vitro experiments using rodent models of sepsis-associated ALI and human pulmonary microvascular endothelial cell line, respectively, we attempted to test the hypothesis that VEGF may contribute to non-cardiogenic high vascular permeability pulmonary edema in ALI associated with sepsis.

\section{Materials and methods}

\section{Experimental animal models}

All animal experimental procedures were conducted in accordance with the National Institute of Health Guidelines on the use of laboratory animal and with approval of the Care and Use Committee of the University of Toyama.

In the first series of experiments, we used the cecal ligation and puncture (CLP)-induced sepsis mouse model. CLP- induced sepsis is regarded as a highly clinically relevant model of polymicrobial sepsis, because it reproduces many hallmarks of sepsis occurring in human patients (Hubbard et al. 2005). The surgical procedure to generate CLP-induced sepsis was conducted according to our previous reports (Tomita et al. 2015; Kawakami et al. 2018; Yamashita et al. 2018). In brief, male BALB/c mice (Sankyo Lab Service, Tokyo Japan), 812 weeks old, were anesthetized with 3-4\% sevoflurane by inhalation, and a middle abdominal incision was made. The cecum was mobilized, tightly ligated $(1 \mathrm{~cm}$ from the cecum tip), punctured twice with a 21 -gauge needle, and gently squeezed to expel small amounts of feces. Then, the bowel was repositioned to the peritoneal cavity, and the laparotomy site was closed with sterile suture (the skin and muscle were sutured separately). Sham-operated control underwent the same procedure except for ligation and puncture of the cecum. Both groups of animals were fed the same diet and water ad libitum, and housed in an environment with controlled temperature, constant humidity, and a daily 12-h light-dark cycle (Yamashita et al. 2018). All animals after CLP surgery were lethargic, showed lack of interest in their environment, displayed piloerection, and had crusty exudates around their eyes, as opposed to sham-operated animals that were healthy, moving freely and eating (Matsuda et al. 2010). All mice received subcutaneous injection of $0.5 \mathrm{ml}$ sterile normal saline immediately after surgery. At $18 \mathrm{~h}$ after surgery, blood samples were collected and inflation-fixed lungs were harvested from mice treated with $80-100 \mathrm{mg} / \mathrm{kg}$ ketamine and $10 \mathrm{mg} / \mathrm{kg}$ xylazine hydrochloride.

In the second series of experiments, mice, under light anesthesia, were instilled intranasally with $60 \mu \mathrm{g}$ of lipopolysaccharide (LPS) (Escherichia coli 055:B5; List Biological Laboratories, Campbell, CA, USA) in $60 \mu \mathrm{l}$ of sterile $0.9 \%$ $\mathrm{NaCl}$ solution. Control animals received equivalent volume of vehicle saline solution. When bevacizumab, which neutralizes VEGF and blocks its signal transduction through VEGF receptors (Papadopoulos et al. 2012), was used, it was intravenously given to mice at a dose of $40 \mu \mathrm{g}$ at $60 \mathrm{~min}$ before administration of LPS. Animals were euthanized at $24 \mathrm{~h}$ after LPS challenge. All experimental data were analyzed in a blinded fashion.

\section{Cell culture}

The immortalized human pulmonary microvascular endothelial cell line (HPMEC-ST1.6R), which was developed by means of co-transfection of a plasmid encoding the catalytic component of telomerase and a plasmid encoding the simian virus 40 large $\mathrm{T}$ antigen (Krump-Konvalinkova et al. 2001; Unger et al. 2002), was kindly provided by Drs. C. James Kirkpatrick and Ronald E. Unger at Johannes Gutenberg University (Mainz, Germany). HPMEC-ST1.6R cells were routinely maintained on tissue culture plastic ware in M199 medium (Sigma- 
Aldrich, St. Louis, MO, USA) supplemented with $20 \%(v / v)$ heat-inactivated fetal bovine serum, $25 \mu \mathrm{g} / \mathrm{ml}$ endothelial cell growth supplements (Sigma-Aldrich), $50 \mu \mathrm{g} / \mathrm{ml}$ sodium heparin (Sigma-Aldrich), $1 \%(\mathrm{v} / \mathrm{v})$ penicillin/streptomycin (Nacalai Tesque, Kyoto, Japan), and $50 \mu \mathrm{g} / \mathrm{ml} \mathrm{G418} \mathrm{(Nacalai} \mathrm{Tesque).}$ Cells were cultured at $37{ }^{\circ} \mathrm{C}$ under a humidified atmosphere containing $5 \% \mathrm{CO}_{2}$ and $95 \%$ air.

In HPMEC-ST1.6R cells, the presence of interferon (IFN)- $\gamma$ can highly amplify the inflammatory responses to LPS (Suzuki et al. 2018). Thus, cells were stimulated with $1 \mu \mathrm{g} / \mathrm{ml} \mathrm{LPS}$ and $10 \mathrm{ng} / \mathrm{ml}$ IFN- $\gamma$ (R\&D Systems, Minneapolis, MN, USA). When mitogen-activated protein kinase (MAPK) inhibitors, PD98059 $(30 \mu \mathrm{M}$; Cayman Chemical, Ann Arbor, MI, USA), SB203580 (20 $\mu$ M; Adipogen Life Sciences, Epalinges, Switzerland), SP600125 $(50 \mu \mathrm{M}$; Cayman Chemical), and JNK-IN-8 $(1 \mu \mathrm{M}$; Merck, Darmstadt, Germany) were used, they were added to the medium for $60 \mathrm{~min}$ before challenge with LPS and IFN- $\gamma$. LPS/ IFN- $\gamma$ stimulation was stopped at the indicated time points by aspirating off the culture medium and then adding ice-cold PSS before harvesting.

\section{Enzyme immunoassay for cytokines and VEGF}

Blood levels of tumor necrosis factor (TNF)- $\alpha$, interleukin (IL)-1 $\beta$, IL-6, and monocyte chemoattractant protein-1 (MCP-1) were measured by the use of commercially available enzyme-linked immunosorbent assay (ELISA) kit (R\&D Systems, Minneapolis, MN) according to the manufacturer's instructions. To measure the concentrations of VEGF in serum and culture medium samples, Mouse VEGF Quantikine ELISA Kit (R\&D System) and Human VEGF DuoSet ELISA (R\&D System) were used, respectively. The plate was read on a microplate reader (Nippon-InterMed, Tokyo, Japan). Assays were performed in duplicate.

\section{Evaluation of pulmonary microvascular leak}

To estimate pulmonary microvascular permeability, IgM was selected as a marker of permeability and its concentration in bronchoalveolar lavage (BAL) fluid was determined immunologically by IgM Mouse Uncoated ELISA Kits with Plates (Thermo Fisher Scientific, Rockford, IL, USA). A polyethylene catheter was inserted into the trachea, BAL was performed by repeatedly infusing and removing $1 \mathrm{ml}$ of PBS, and the third drainage of effluent was kept as BAL fluid.

\section{RNA extraction and quantitative real-time polymer- ase chain reaction (PCR)}

Total RNA was isolated from HPMEC-ST1.6R cells and lung tissues with the use of Sepazol@-RNA I Super G
(Nacalai Tesque) according to the manufacturer's manual. ReverTra Ace qPCR RT Master Mix (Toyobo, Osaka, Japan) was used for the reverse transcription reaction, and real-time PCR analyses were performed using PowerUp ${ }^{\mathrm{TM}}$ SYBR® Green Master Mix (Thermo Fisher Scientific), as described in the manufacturers' instructions. Values were normalized to the housekeeping gene GAPDH according to the manufacturer's protocol (MX3000P real-time PCR system; Agilent Technologies Inc., Santa Clara, CA, USA). Additional details are described by our laboratory (Kawakami et al. 2018; Yamashita et al. 2018; Suzuki et al. 2018). The PCR primers were designed as follows: forward 5'TGCAGATTATGCGGATCAAACC-3' and reverse 5' TGCATTCACATTTGTTGTGCTGTAG-3' for VEGF, forward 5'-CAGGCCCAGTTTCTGCCATT-3' and reverse 5'-TTCCAGCTCAGCGTGGTCGTA-3' for VEGFR1, forward 5'-CCAGCAAAAGCAGGGAGTCT GT-3' and reverse 5'-TGTCTGTGTCATCGGAGTGA TATCC-3' for VEGFR2, and forward 5'-TGTG TCCGTCGTGGATCTGA-3' and reverse $5^{\prime}$-TTGC TGTTGAAGTCGCAGGAG-3' for glyceraldehyde-3phosphate dehydrogenase (GAPDH).

\section{Western blot analysis}

HPMEC-ST1.6R cells were grown in 100-mm dish, harvested, and lysed in $300 \mu \mathrm{l}$ of RIPA buffer $(25 \mathrm{mM}$ Tris- $\mathrm{HCl}, 150 \mathrm{mM} \mathrm{NaCl}, 1 \% \mathrm{NP}-40,1 \%$ sodium deoxycholate, $0.1 \%$ SDS, $\mathrm{pH}$ 7.4) containing protease inhibitor cocktail on ice. The lysates were centrifuged at $18,000 \times g$ for $10 \mathrm{~min}$ at $4{ }^{\circ} \mathrm{C}$ and the resulting supernatants were collected. The protein concentration in the remaining supernatant was measured using BCA Protein Assay Kit (Nacalai Tesque). Blotting procedure, chemiluminescent detection, and densitometric analysis were carried out as described in our previous reports (Kawakami et al. 2018; Suzuki et al. 2018). Samples (50-100 $\mu \mathrm{g}$ of protein) were separated with $10 \%$ SDSPAGE gel electrophoresis and then transferred to polyvinylidene difluoride filter membrane. The membrane was probed with the following primary antibodies: anti-human extracellular signal-regulated protein kinase (ERK) 1/2 mouse monoclonal antibody (1:1000; Cell Signaling, Danvers, MA, USA), anti-human phospho-ERK1/2 (Thr-202/Tyr-204) rabbit monoclonal antibody (1:1000; Cell Signaling), anti-human c-Jun Nterminal kinase (JNK) rabbit monoclonal antibody (1:1000; Cell Signaling), anti-human p38 rabbit monoclonal antibody (1:1000; Cell Signaling), anti-human phospho-p38 (Thr-180/Tyr-182) mouse monoclonal antibody (1:1000; Cell Signaling), anti-human JNK (Thr183/Tyr-185) mouse monoclonal antibody (1:1000; Cell 
Signaling), and anti-human GAPDH chicken polyclonal antibody (1:1500; EMD Millipore, Billerica, MA, USA). IRDye®-labeled secondary antibodies were purchased from LI-COR Bioscience (Lincoln, NE, USA) and Odyssey CLx Infrared Imaging System (LI-COR Bioscience) was employed for primary antibody detection. GAPDH was used as the loading control.

\section{Statistical analysis}

Results are presented as mean \pm standard error. Data were analyzed by the use of Prism software (version 6; GraphPad Software, San Diego, CA, USA). Statistical analysis was performed by Student's $t$ test or one-way analysis of variance (ANOVA) followed by Tukey's multiple-comparison test. Differences were considered to be statistically significant when a $P$ value was $<0.05$.

\section{Results}

\section{VEGF expression in mice with CLP-induced sepsis}

The CLP rodent model, which causes peritonitis and leads to a polymicrobial sepsis, represents an indirect insult similar to the pathogenesis of ALI/ARDS (Villar et al. 1994). Indeed, we have clearly demonstrated that mice 18-24 h after CLP surgery display marked hypoxemia, increased lung vascular permeability, and histological damage in lungs, including wall thickening, inflammatory infiltrate, and hemorrhage (Takano et al. 2011; Oishi et al. 2012; Imaizumi et al. 2018).

When blood levels of pro-inflammatory cytokines were measured using an ELISA, the sham-operated control animals had extremely low levels of the cytokines examined here. The mice $18 \mathrm{~h}$ after CLP-induced sepsis exhibited marked elevations in blood levels of TNF- $\alpha$, IL-1 $\beta$, IL-6, and MCP-1

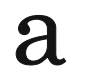

TNF- $\alpha$
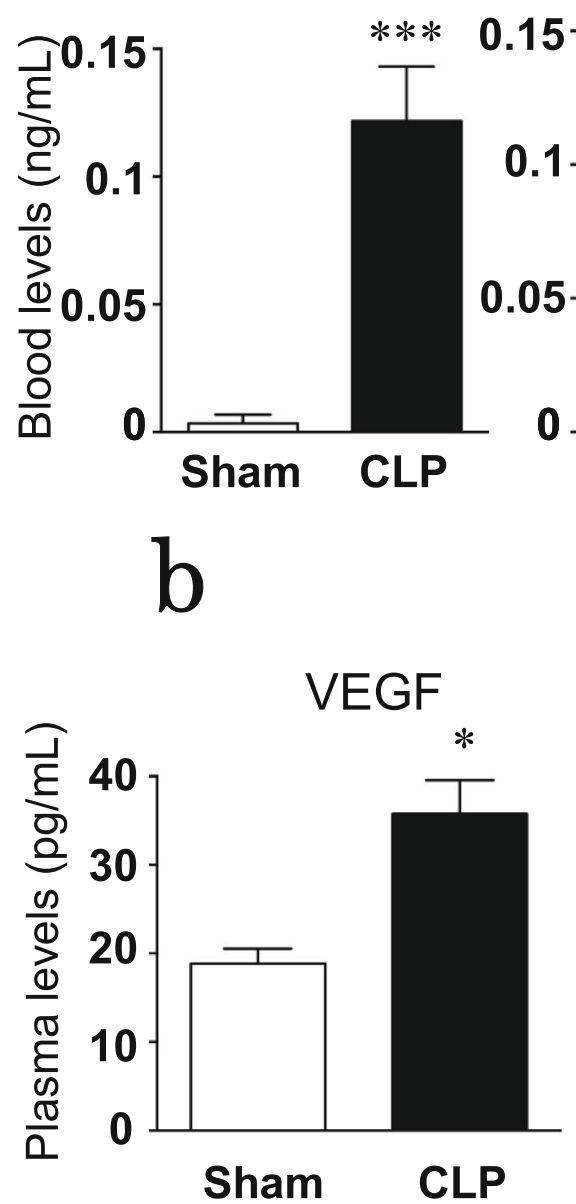

Fig. 1 VEGF expression in mice with CLP-induced sepsis. (a) Blood levels of TNF- $\alpha$, IL-1 $\beta$, IL-6, and MCP-1 $(n=6)$. (b) Plasma levels of VEGF $(n=3-5)$. The blood was collected $18 \mathrm{~h}$ after surgery. Proinflammatory cytokines and VEGF were measured by an ELISA.

IL-1 $\beta$

C
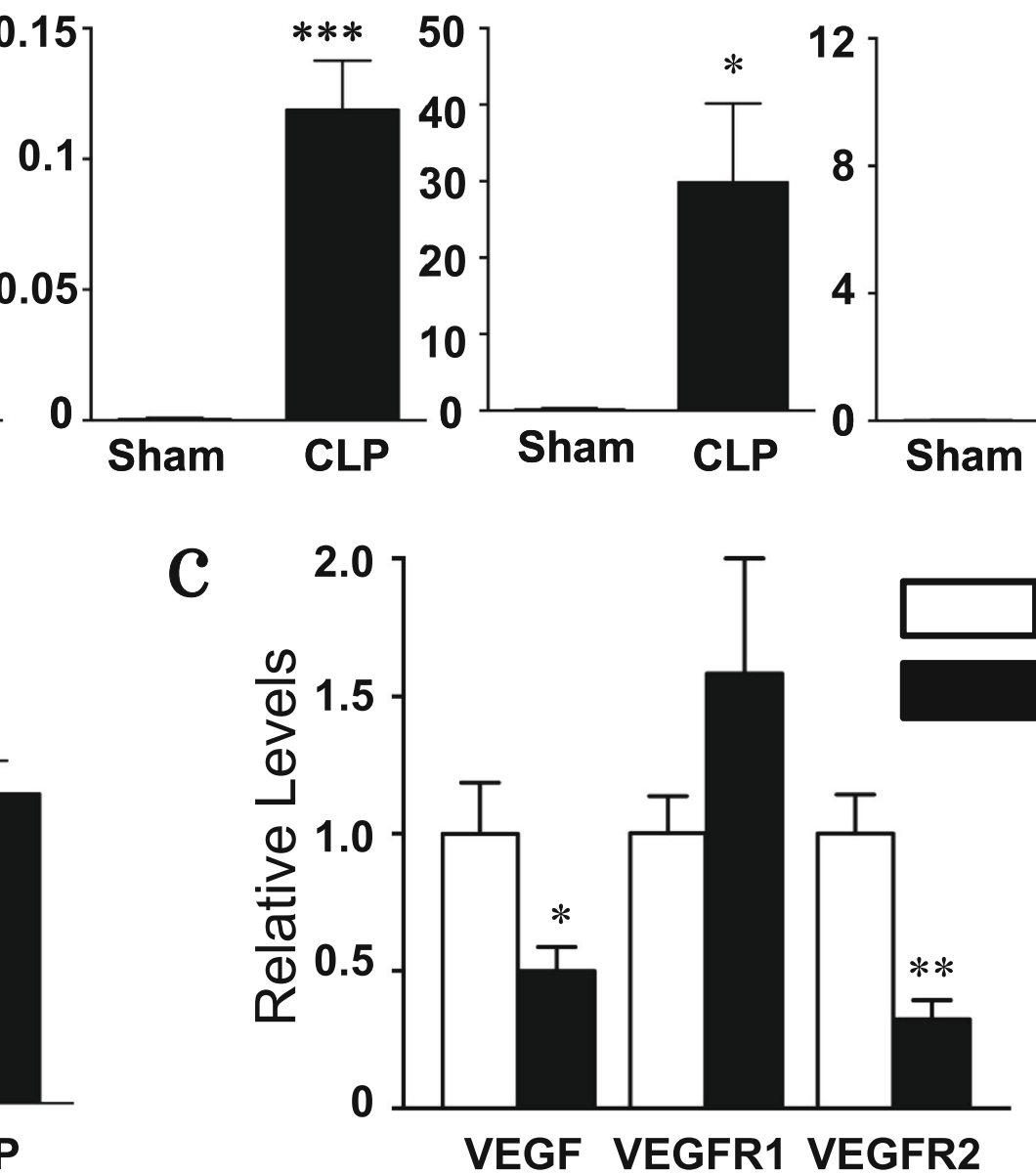

(c) The mRNA levels of VEGF, VEGFR1, and VEGFR2 in lung tissues were quantified by real-time PCR. Lung tissues were harvested $18 \mathrm{~h}$ after surgery. Values are normalized to GAPDH $(n=6) .{ }^{*} P<0.05,{ }^{* *} P<0.01$, and ${ }^{* * *} P<0.001$ vs. the sham-operated control group 
(Fig. 1a). Sepsis induction by CLP also resulted in a significant elevation in plasma VEGF protein levels in mice (Fig. 1b). Plasma VEGF in CLP mice was increased 2.1-fold in comparison with sham-operated control animals. However, the VEGF mRNA level was significantly downregulated in lung tissues from mice with CLP-induced sepsis (Fig. 1c). We further examined VEGFR mRNA levels in CLP mouse lungs. VEGF regulates vascular permeability by activating 2 receptors, VEGFR1 (Flt-1) and VEGFR2 (KDR/Flk1) (Shibuya 2011). As shown in Fig. 1c, VEGFR1 mRNA was increased and VEGFR2 mRNA was decreased in lung tissues of CLP mice compared with sham-operated controls.

\section{Pulmonary vascular permeability in mice intranasally instilled with LPS}

To assess changes in pulmonary vascular permeability, BAL supernatant was analyzed for IgM using an ELISA. Intranasal challenge with LPS resulted in a highly significant 14.5 -fold increase in pulmonary vascular permeability (Fig. 2a). Treatment with bevacizumab, which neutralizes VEGF and blocks VEGFR signaling (Papadopoulos et al. 2012), significantly but partially attenuated lung vascular permeability as compared with that shown in mice challenged with LPS alone.

We also examined VEGF mRNA levels in lung tissues of mice intranasally instilled with LPS. As seen in CLP-induced septic mice, pulmonary mRNA expression was significantly downregulated in mice challenged with LPS (Fig. 2b).

\section{VEGF expression in human pulmonary microvascular endothelial cells}

In the immortalized human pulmonary microvascular endothelial cell line HPMEC-ST1.6R, the time course of changes in gene expression of VEGF and its receptors after coadministration of LPS and IFN- $\gamma$ were investigated. The mRNA level of VEGF was gradually increased, reached a maximum at 3-6 h, and then showed a return toward the baseline at $24 \mathrm{~h}$ (Fig. 3a). The mRNA level of VEGFR1 showed a trend toward increasing throughout 3-24 h observation period (Fig. 3b). VEGFR2 mRNA remained virtually unchanged in a wide range of time after stimulation with LPS and IFN- $\gamma$ (Fig. 3c). When the amounts of VEGF in culture media were measured by an ELISA, LPS/IFN- $\gamma$ challenge resulted in a significant increase in the protein level of VEGF (Fig. 4b).

The MAPK signaling cascades are generally thought to be important in the pathogenesis of ALI/ARDS (Newton and Holden 2006; Qian et al. 2016). When activation of the three major subgroups of MAPK family, ERK1/2, p38, and JNK, was assessed by increases in their phosphorylation levels, coadministration of LPS and IFN- $\gamma$ resulted in significant activation of all three families of MAPKs in HPMEC-ST1.6R a

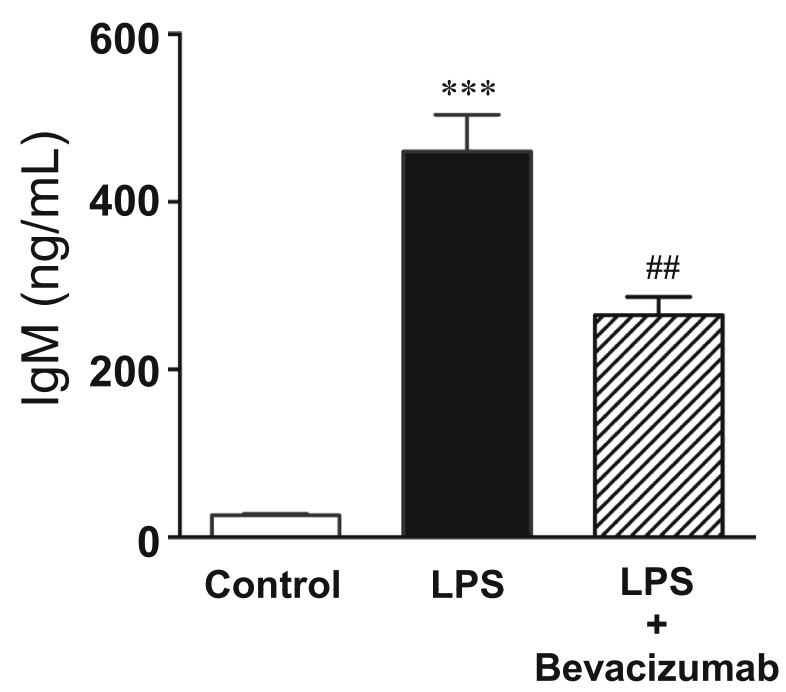

$\mathrm{b}$

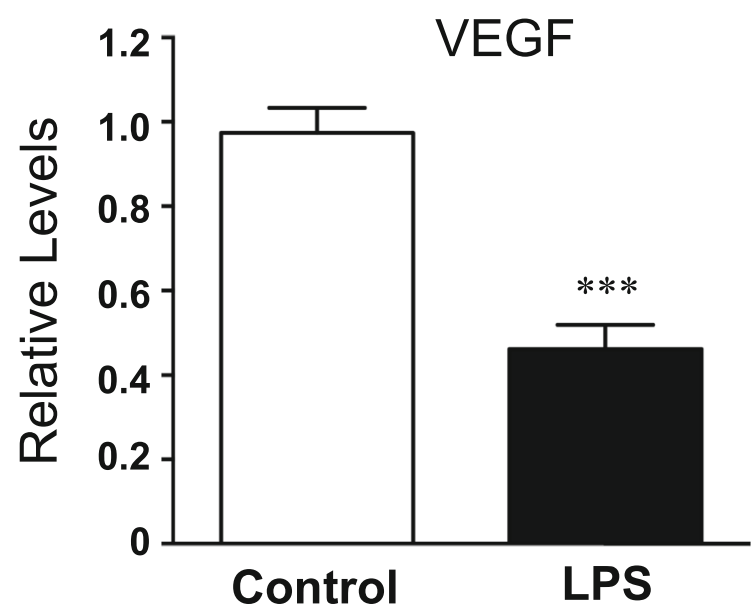

Fig. 2 Involvement of VEGF in lung vascular hyperpermeability in mice after LPS administration. LPS $(60 \mu \mathrm{g})$ was instilled intranasally and animals were euthanized at $24 \mathrm{~h}$ after LPS challenge. (a) Lung vascular permeability was assessed by IgM levels in BAL fluid from mouse lungs $(n=3-4)$. Bevacizumab $(40 \mu \mathrm{g})$ was intravenously injected to mice 60 min before LPS challenge. (b) The mRNA levels of VEGF in lung tissues were quantified by real-time PCR. Values are normalized to GAPDH $(n=5) .{ }^{* * * *} P<0.001$ vs. control. ${ }^{\# \#} P<0.01$ vs. LPS alone

cells (Fig. 4a). We thus examined whether expression of VEGF in human pulmonary microvascular endothelial cells is regulated by MAPKs. When HPMEC-ST1.6R cells were treated with PD98059, an inhibitor of MAPK kinase which is an ERK1/2 upstream activator, or SB203580, which is widely used as a specific inhibitor of p38 MAPK, the LPS/IFN- $\gamma$ induced increase in VEGF protein levels was strongly blocked (Fig. 4b). Treatment with SP600125, an anthrapyrazolone inhibitor of JNK, also abrogated the VEGF protein increase in HPMEC-ST1.6R cells stimulated with LPS/IFN- $\gamma$ (Fig. 4b). The striking inhibition of the LPS/IFN- $\gamma$-induced VEGF upregulation was similarly observed by treatment with another 


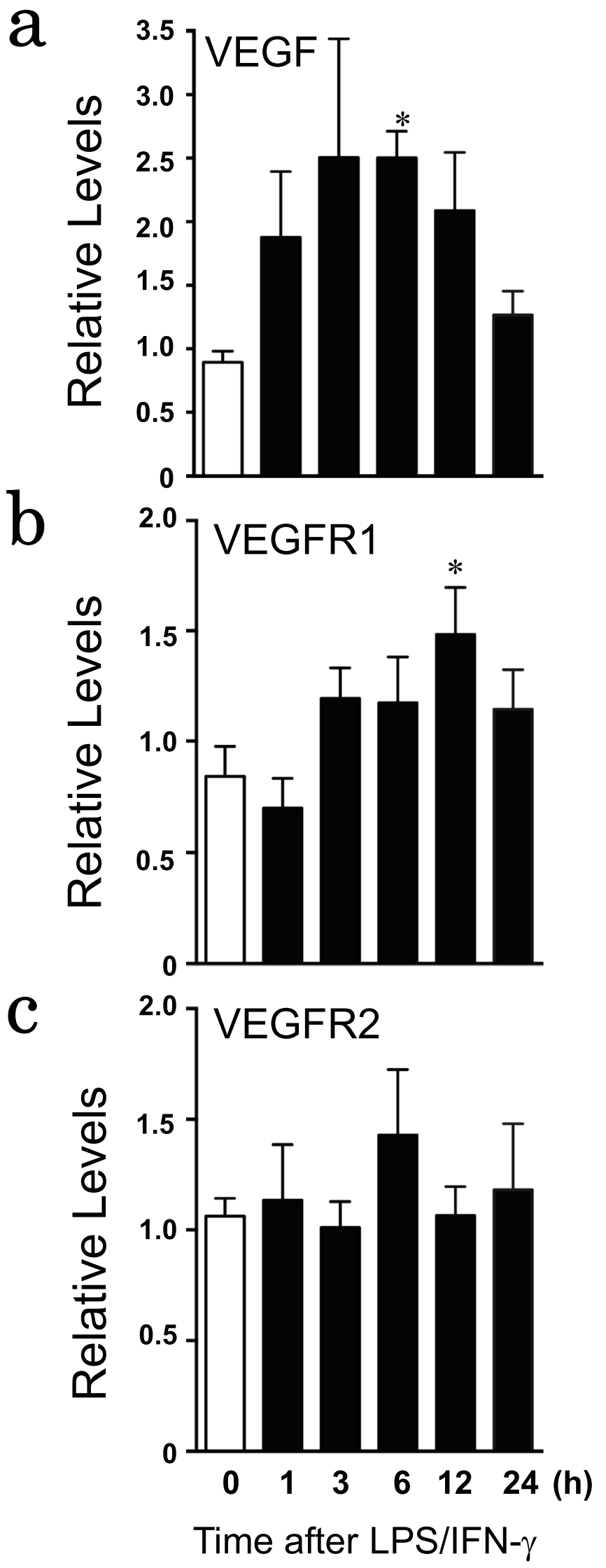

Fig. 3 Time course of changes in mRNA levels of VEGF (a), VEGFR1 (b), and VEGFR2 (c) in human pulmonary microvascular endothelial cells after challenge with LPS and IFN- $\gamma$. HPMEC-ST1.6R cells were stimulated with $1 \mu \mathrm{g} / \mathrm{ml}$ LPS and $10 \mathrm{ng} / \mathrm{ml} \mathrm{IFN}-\gamma$. Values are expressed as fold increase above the vehicle value normalized GAPDH $(n=5-7)$. ${ }^{*} P<0.05$ vs. time 0

JNK inhibitor JNK-IN-8, which is far more selective for JNK than SP600125 (Brain et al. 2003) (Fig. 4b).

\section{Discussion}

We demonstrated in this study for the first time that VEGF contributed to pulmonary vascular hyperpermeability when LPS was intranasally administrated in mice. Intranasal administration of LPS has long been widely used as an appropriate model in which ALI can be directly induced (Gharib et al. 2006; Bosmann et al. 2013; Juschten et al. 2019), and increased pulmonary vascular permeability is a critical and non-redundant pathological process involved in the ALI development (Herold et al., 2013). We found that treatment with the VEGF-neutralizing monoclonal antibody bevacizumab resulted in a significant inhibition of the increase in pulmonary vascular permeability caused by intranasal LPS challenge, as evidenced by changes in IgM levels in BAL fluid from mouse lungs. Previous reports have well established that the amounts of IgM in BAL fluid are related with alterations in alveolarcapillary barrier and lung vascular permeability (Kantrow et al. 2009; Matute-Bello et al. 2011; Johnston et al. 2012). Intriguingly, while bevacizumab is clinically used for treatment of advanced cancers of the lung, colon, brain, kidney, and others by counteracting the angiogenic effect of VEGF, its ability to reduce the increase in vascular permeability associated with VEGF expression may help relieve patients with the potentially serious morbidity and symptoms that accompany peritumoral edema (Gil-gil et al. 2013). Our findings imply the active participation of VEGF in non-cardiogenic high vascular permeability pulmonary edema associated with LPSinduced ALI (Fig. 5). However, the preventive effect of bevacizumab on LPS-induced pulmonary vascular hyperpermeability was partial. Our previous study has shown that treatment with $N^{\mathrm{G}}$-nitro-L-arginine, an inducible nitric oxide (NO) synthase (iNOS) inhibitor, or diphenhydramine, a histamine $\mathrm{H}_{1}$-receptor antagonist, significantly but incompletely inhibited LPS-induced lung vascular permeability in mice (Matsuda et al. 2004), which suggests that NO and histamine may also be partly responsible for mediating increased lung vascular leak following LPS challenge. We thus assume that several vascular permeability molecules, including VEGF, NO, and histamine, can be excessively produced and thereby actually contribute to the development of pulmonary edema in sepsis-associated ALI. Indeed, great increases in 
Fig. 4 Involvement of MAPK activation in VEGF released from human pulmonary microvascular endothelial cells after challenge with LPS and IFN- $\gamma$. HPMECST1.6R cells were stimulated with $1 \mu \mathrm{g} / \mathrm{ml}$ LPS and $10 \mathrm{ng} / \mathrm{ml}$ IFN- $\gamma \cdot$ (a) Activation of MAPKs in HPMEC-ST1.6R after challenge with LPS and IFN- $\gamma$. Levels of phosphorylation and total expression of ERK1/2, p38, and JNK before and $5 \mathrm{~min}$ after LPS/IFN- $\gamma$ challenge were determined by Western blotting. In the top trace of each panel, typical Western blots are shown. In the bottom trace, the summary of quantification of densitometric measurements as ratio of phospho-MAPK relative to MAPK is presented $(n=4-7)$. ${ }^{*} P<0.05$ and ${ }^{* *} P<0.01$ vs. unstimulated value. (b) Effects of MAPK inhibitors on VEGF levels in HPMEC-ST1.6R cells stimulated with LPS/IFN- $\gamma$ for 24 h. PD98059 $(30 \mu \mathrm{M})$, SB203580 $(20 \mu \mathrm{M})$, SP600125 $(50 \mu \mathrm{M})$, or JNK-IN-8 $(1 \mu \mathrm{M})$ was added $1 \mathrm{~h}$ before LPS/IFN- $\gamma$ challenge. The VEGF levels released from cells into the cell culture medium were measured by an ELISA $(n=4) .{ }^{* *} P<0.01$ vs. control. ${ }^{\# \#} P<0.001$ vs. LPS/ IFN- $\gamma$ alone a

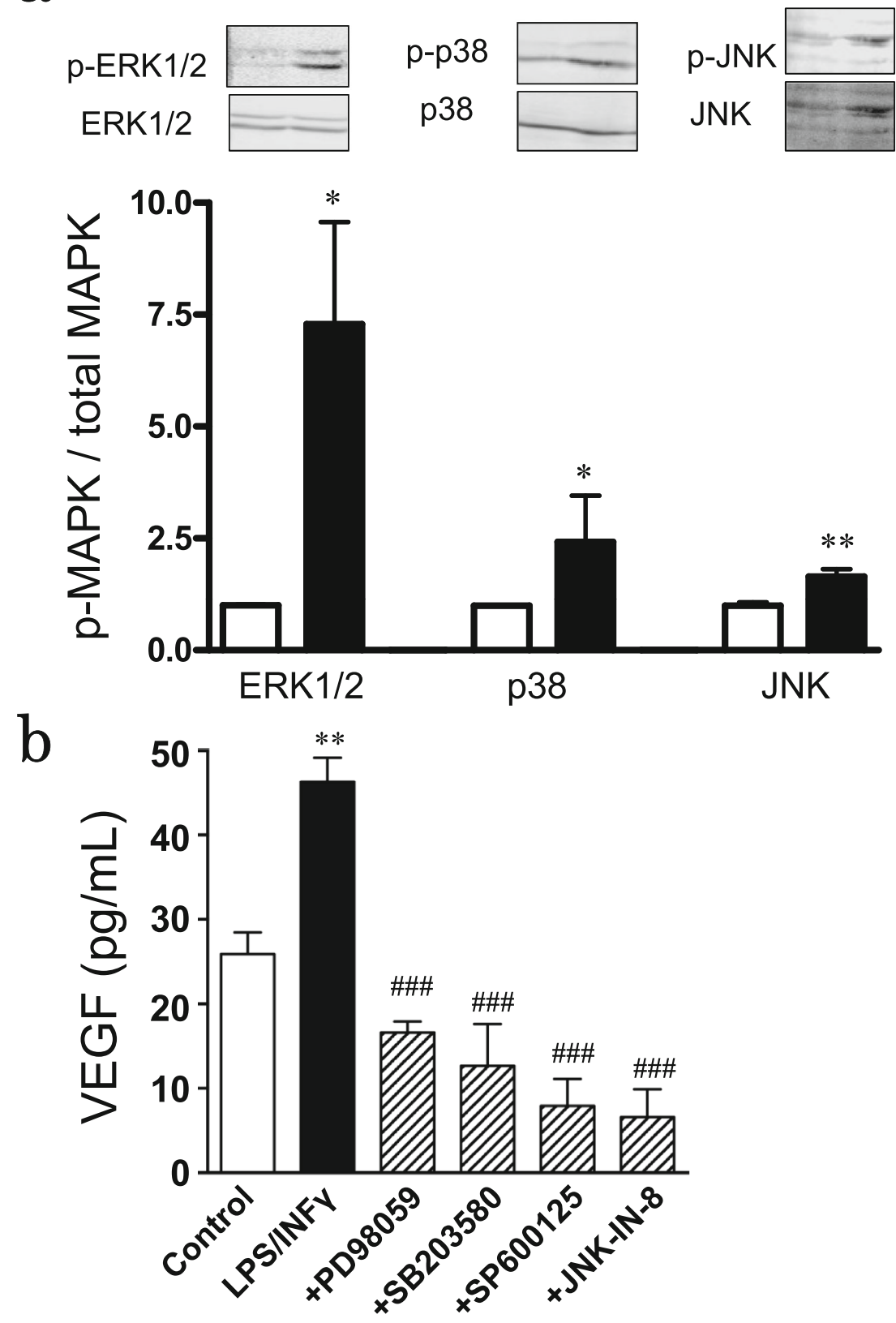

gene and protein expression of iNOS and histidine decarboxylase, an enzyme that only forms histamine in mammals, have been observed in the lungs of mice after induction of sepsis with LPS (Matsuda et al. 2004).

Unexpectedly, expression of VEGF in lung tissues was significantly downregulated rather than upregulated in two murine models of ALI, intranasal LPS administration and CLP-induced sepsis. This observation is consistent with a string of human studies showing a reduction in intrapulmonary VEGF in the early stages of ALI/ARDS (Maitre et al. 2001; Thickett et al. 2002; Abadie et al. 2005), although a conflicting result was reported in mice exposed to LPS in a nebulization chamber (Karmpaliotis et al. 2002). The reduced levels of intrapulmonary VEGF in ALI/ARDS may be explained by direct injury to and clearance of epithelial type 2 cells (Medford and Millar 2006) which are considered to be the main source of VEGF in lungs (Kaner and Crystal 2001). In this regard, caution would be required in the interpretation of the observed decrease in VEGF levels in lung tissues, since the total amount of intrapulmonary VEGF may be determined by the deduction of VEGF released from different intrapulmonary components, such as epithelial cells and vascular endothelial cells, which can be variably affected by endotoxin. As reported in human studies (Maitre et al. 2001; Thickett et al. 2002; Azamfirei et al. 2010), we found a significant rise in plasma levels of VEGF in mice with CLP- 
Fig. 5 Schematic diagram of the participation of VEGF released from pulmonary vascular endothelial cells in noncardiogenic high vascular permeability pulmonary edema associated with LPS-induced ALI. See text for details

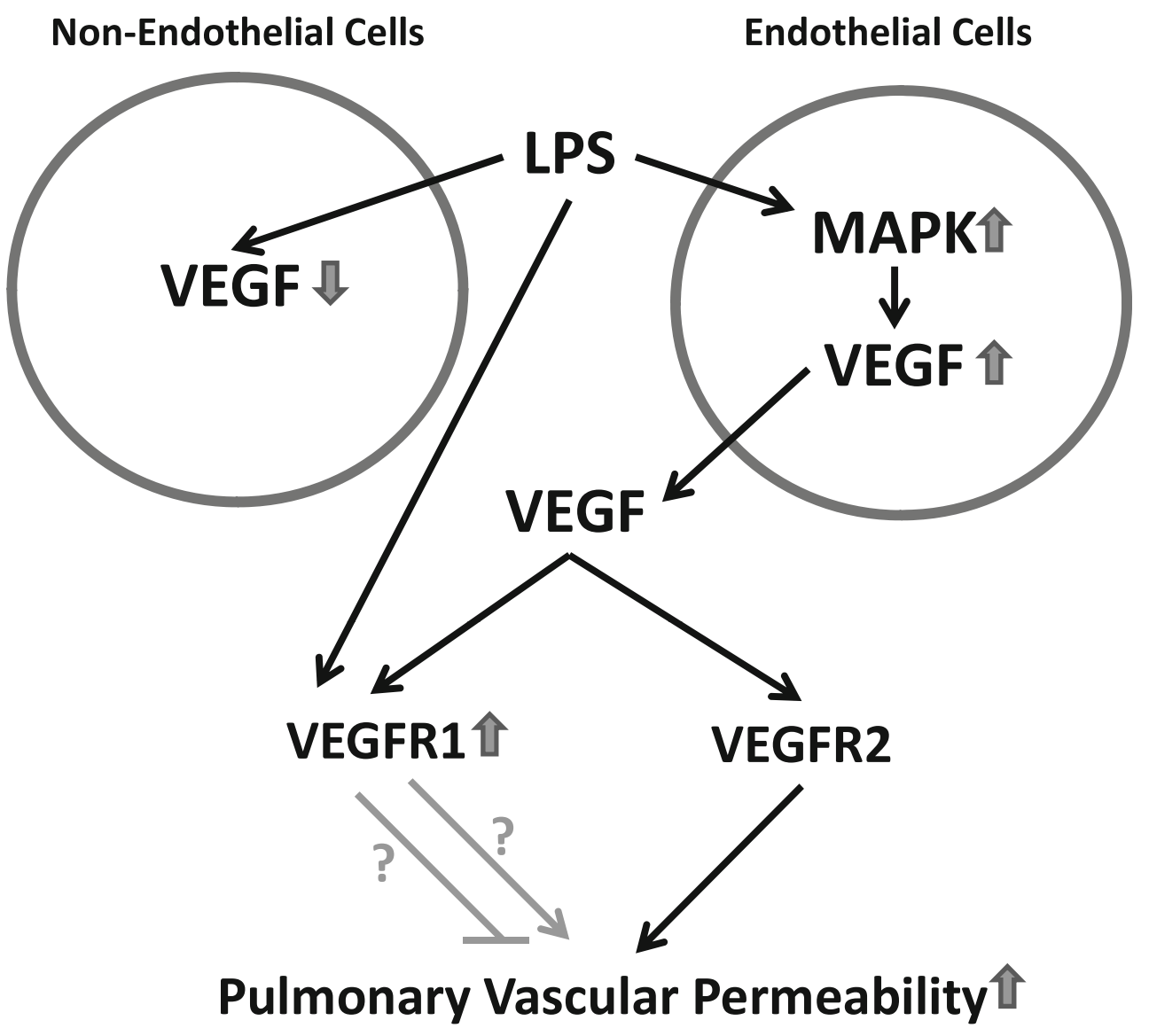

$\downarrow$

induced sepsis. This rise in plasma VEGF levels seems likely to be attributed to the release from vascular endothelial cells. We showed that stimulation with LPS/IFN- $\gamma$ resulted in a significant upregulation of VEGF expression in human pulmonary microvascular endothelial cells at mRNA and protein levels, implying that endotoxin positively regulates endothelial cell-derived VEGF in a transcription manner. It should be added that neutrophils may also contribute to the increased VEGF plasma levels in CLP-induced septic mice, because these hemocytes have been shown to produce various vascular permeability molecules, including VEGF, in certain circumstances such as inflammation (Taichman et al. 1997; DiStasi and Ley 2009).

In line with our recent report (Suzuki et al. 2018), stimulation with LPS/IFN- $\gamma$ significantly activated three major subgroups of MAPK family, ERK1/2, p38, and JNK, in human pulmonary microvascular endothelial cells, as assessed by their phosphorylation levels. Each specific inhibitor of these MAPK subgroups completely blocked the increase in VEGF protein levels caused by LPS/IFN- $\gamma$ challenge. This suggests that endotoxin upregulates VEGF expression in pulmonary microvascular endothelial cells through multiple MAPKdependent pathways. It is noteworthy that MAPK signaling is linked to increased expression of growth factors, including VEGF, in different cell types (Li et al. 2000; Pagès et al. 2000; Rak et al. 2000; Schrma et al. 2011).

VEGF displays broad vascular functions, including vascular permeability, via binding to and activating its specific receptors, VEGFR1 and VEGFR2 (Shibuya 2011). In this study, in lung tissues from CLP-induced septic mice, VEGFR1 mRNA was upregulated and VEGFR2 mRNA was downregulated compared with sham-operated controls. Furthermore, LPS/IFN- $\gamma$ application showed a trend to increase VEGFR1 mRNA in human pulmonary microvascular 
endothelial cells. However, it is not clear at this time whether altered expression of VEGFR1 can be involved as regulatory mechanisms to transduce VEGF-mediated vascular hyperpermeability signals. Several lines of evidence provide that VEGFR1 may function as a decoy receptor and negatively regulate VEGF functions (Sato et al. 2000; Cao 2009). Accordingly, what role, if any, is played by altered VEGFR1 expression observed in this study in the pathophysiology of sepsis-associated ALI awaits further study.

In conclusion, the present results indicate that VEGF can contribute to the development of non-cardiogenic pulmonary edema in sepsis-associated ALI as a result of increased VEGF secretion from pulmonary vascular endothelial cells through multiple MAPK-dependent pathways (Fig. 5). As such, antiVEGF therapy may be of value in ALI/ARDS. However, it is proposed that VEGF also displays a protective effect on the alveolar epithelium following injury (Medford and Millar 2006). Therefore, a deeper understanding of the role of VEGF in the lung will be required before treatment modulating VEGF may be used in ALI/ARDS. Thus, it remains the subject of our ongoing study to precisely grasp VEGF biology in the body, including the lungs, under sepsis.

Acknowledgments We thank Drs. Takahiro Imaizumi and Takuya Sakamoto for their expert help in the commencing time of this study.

Author contributions K.T., N.M., and Y.H. conceived and designed the experiments. K.T.,, Y.S., T.S., and S.I. performed the experiments. K.T., Y.S., and T.S. analyzed data. K.H. and Y.H. wrote the article. All authors read and approved the manuscript. The authors declare that all data were generated in-house and that no paper mill was used.

Funding information This study was supported by Grant-in-Aid for Young Scientists (17 K15578, 20 K17776) and for Scientific Research (17 K08586, 19H03757) from Japan Society for Promotion of Science.

\section{Compliance with ethical standards}

All animal studies were approved by the Animal Care and Use Committee of the University of Toyama, which are based on the National Institute of Health Guide for the Care and Use of Laboratory Animals and the ARRIVE guidelines.

Conflict of interest The authors declare that they have no conflict of interest.

\section{References}

Abadie Y, Bregeon F, Papazian L, Lange F, Chailley-Heu B, Thomas P, Duvaldestin P, Adnot S, Maitre B, Delclaux C (2005) Decreased VEGF concentration in lung tissue and vascular injury during ARDS. Eur Respir J 25:139-146

Azamfirei L, Gurzu S, Solomon R, Copotoiu R, Copotoiu S, Jung T, Tilinca M, Branzaniuc K, Corneci D, Szederjesi J, Kovacs J (2010) Vascular endothelial growth factor: a possible mediator of endothelial activation in acute respiratory distress syndrome. Minerva Anestesiol 76:609-616
Barratt S, Medford AR, Millar AB (2014) Vascular endothelial growth factor in acute lung injury and acute respiratory distress syndrome. Respiration 87:329-342

Bates DO (2010) Vascular endothelial growth factors and vascular permeability. Cardiovasc Res 87:262-271

Bosmann M, Grailer JJ, Russkamp NF, Ruemmler R, Zetoune FS, Sarma JV, Ward PA (2013) CD11 $\mathrm{c}^{+}$alveolar macrophages are a source of IL-23 during lipopolysaccharide-induced acute lung injury. Shock 39:447-452

Brain J, McLauchlan H, Elliott M, Cohen P (2003) The specificities of protein kinase inhibitors: an update. Biochem J 371:199-204

Cao Y (2009) Positive and negative modulation of angiogenesis by VEGFR1 ligands. Sci Signal 2:59

DiStasi MR, Ley K (2009) Opening the flood-gates: how neutrophilendothelial interactions regulate permeability. Trends Immunol 30: $547-556$

Ferrara N (2004) Vascular endothelial growth factor: basic science and clinical progress. Endocr Rev 25:581-611

Gerber HP, McMurtrey A, Kowalski J, Yan M, Keyt BA, Dixit V, Ferrara N (1998) Vascular endothelial growth factor regulates endothelial cell survival through the phosphatidylinositol 3'-kinase/Akt signal transduction pathway. Requirement for Flk-1/KDR activation. J Biol Chem 273:30336-30343

Gharib SA, Liles WC, Matute-Bello G, Glenny RW, Martin TR, Altemeier WA (2006) Computational identification of key biological modules and transcription factors in acute lung injury. Am J Respir Crit Care Med 173:653-658

Gil-gil MJ, Mesia C, Rey M, Bruna J (2013) Bevacizumab for the treatment of glioblastoma. Clin Med Insights Oncol 7:123-135

Godzich M, Hodnett M, Frank JA, Su G, Pespeni M, Angel A, Howard MB, Matthay MA, Pittet JF (2006) Activation of the stress protein response prevents the development of pulmonary edema by inhibiting VEGF cell signaling in a model of lung ischemiareperfusion injury in rats. FASEB J 20:1519-1521

Hubbard WJ, Choudhry M, Schwacha MG, Kerby JD, Rue LW 3rd, Bland KL, Chaudry IH (2005) Cecal ligation and puncture. Shock 24(Suppl 1):52-57

Imaizumi T, Matsuda N, Tomita K, Palikhe S, Ohashi W, Hattori K, Hattori Y (2018) Activator protein-1 decoy oligodeoxynucleotide transfection is beneficial in reducing organ injury and mortality in septic mice. Crit Care Med 46:e435-e442

Johnston LK, Rims CR, Gill SE, McGuire JK, Manicone AM (2012) Pulmonary macrophage subpopulations in the induction and resolution of acute lung injury. Am J Respir Cell Mol Biol 47:417-426

Juschten J, Ingelse SA, Maas MAW, Girbes ARJ, Juffermans NP, Schultz MJ, Tuinman PR (2019) Antithrombin plus alpha-1 protease inhibitor does not affect coagulation and inflammation in two murine models of acute lung injury. Intensive Care Med Exp 7(Suppl 1):36

Kaner RJ, Crystal RJ (2001) Compartmentalization of vascular endothelial growth factor to the epithelial surface of the human lung. Mol Med 7:240-246

Kaner RJ, Ladetto JV, Singh R, Fukuda N, Matthay MA, Crystal RG (2000) Lung overexpression of the vascular endothelial growth factor gene induces pulmonary edema. Am J Repir Cell Mol Biol 22: 657-664

Kantrow SP, Shen Z, Jagneaux T, Zhang P, Nelson S (2009) Neutrophilmediated lung permeability and host defense proteins. Am J Physiol Lung Cell Mol Physiol 297:L738-L745

Karmpaliotis D, Kosmidou I, Ingenito EP, Hong K, Malhotra A, Sunday ME, Haley KJ (2002) Angiogenic growth factors in the pathophysiology of a murine model of acute lung injury. Am J Physiol Lung Cell Mol Physiol 283:L585-L595

Kawakami M, Hattori M, Ohashi W, Fujimori T, Hattori K, Takebe M, Tomita K, Yokoo H, Matsuda N, Yamazaki M, Hattori Y (2018) Role of $\mathrm{G}$ protein-coupled receptor kinase 2 in oxidative and 
nitrosative stress-related neurohistopathological changes in a mouse model of sepsis-associated encephalopathy. J Neurochem 145:474 488

Krump-Konvalinkova V, Bittinger F, Unger RE, Peters K, Lehr HA, Kirkpatrick CJ (2001) Generation of human pulmonary microvascular endothelial cell lines. Lab Investig 81:1717-1727

Li Z, Shimada Y, Uchida S, Maeda M, Kawabe A, Mori A, Itami A, Kano M, Watanabe G, Imamura M (2000) TGF-alpha as well as VEGF, PD-ECGF and bFGF contribute to angiogenesis of esophageal squamous cell carcinoma. Int J Oncol 17:453-460

Li LF, Huang CC, Liu YY, Lin HC, Kao KC, Yang CT, Liao SK (2011) Hydroxyethyl starch reduces high stretch ventilation-augmented lung injury via vascular endothelial growth factor. Transl Res 157: 293-305

Maitre B, Boussat S, Jean D, Gouge M, Brochard L, Houssat B, Adnot S, Dalclaux C (2001) Vascular endothelial growth factor synthesis in the acute phase of experimental and clinical lung injury. Eur Respir $\mathrm{J}$ $18: 100-106$

Matsuda N, Hattori Y, Takahashi Y, Nishihira J, Jesmin S, Kobayashi M, Gando S (2004) Therapeutic effect of in vivo transfection of transcription factor decoy to NF- $\mathrm{kB}$ on septic lung in mice. Am J Physiol Lung Cell Mol Physiol 287:L1248-L1255

Matsuda N, Teramae H, Yamamoto S, Takano K, Takano Y, Hattori Y (2010) Increased death receptor pathway of apoptotic signaling in septic mouse aorta: effect of systemic delivery of FADD siRNA. Am J Physiol Heart Circ Physiol 298:H92-H101

Matuschak GM, Lechner AJ (2010) Acute lung injury and the acute respiratory distress syndrome: pathophysiology and treatment. Mol Med 107:252-258

Matute-Bello G, Downey G, Moore BB, Groshong SD, Matthay MA, WM SASK, Acute Lung Injury in Animals Study Group (2011) An official American Thoracic Society workshop report: features and measurements of experimental acute lung injury in animals. Am J Respir Cell Mol Biol 44:725-438

Medford ARL, Millar AB (2006) Vascular endothelial growth factor (VEGF) in acute lung injury (ALI) and acute respiratory distress syndrome (ARDS): paradox or paradigm? Thorax 61:621-626

Mura M, Han B, Andrade CF, Seth R, Hwang D, Waddell TK, Keshavjee S, Liu M (2006) The early responses of VEGF and its receptors during acute lung injury: implication of VEGF in alveolar epithelial cell survival. Crit Care 10:R130

Newton R, Holden NS (2006) New aspects of p38 mitogen activated protein kinase (MAPK) biology in lung inflammation. Drug Discov Today Dis Mech 3:53-61

Oishi H, Takano K, Tomita K, Takebe M, Yokoo H, Yamazaki M, Hattori Y (2012) Olprinone and colforsin daropate alleviate septic lung inflammation and apoptosis through CREB-independent activation of the Akt pathway. Am J Physiol Lung Cell Mol Physiol 303:L130-L140

Pagès G, Milanini J, Richard DE, Berra E, Gothié E, Viňals F, Pouysségur J (2000) Signaling angiogenesis via p42/p44 MAP kinase cascade. Ann N Y Acad Sci 902:187-200

Papadopoulos N, Martin J, Ruan Q, Rafique A, Rosconi MP, Shi E, Pyles EA, Yancopoulos GD, Stahl N, Wiegand SJ (2012) Binding and neutralization of vascular endothelial growth factor (VEGF) and related ligands by VEGF trap, ranibizumab and bevacizumab. Angiogenesis 15:171-185

Plouet J, Schilling J, Gospodarowicz D (1989) Isolation and characterization of a newly identified endothelial cell mitogen produced by AtT-20 cells. EMBO J 8:3801-3806

Qian F, Deng J, Wang G, Ye RD, Christman JW (2016) Pivotal role of mitogen-activated protein kinase-activated protein kinase 2 in inflammatory pulmonary diseases. Curr Protein Pept Sci 17:332-342
Rak J, Mitsuhashi Y, Sheehan C, Tamir A, Viloria-Petit A, Filmus J, Mansour SJ, Ahn NG, Kerbel RS (2000) Oncogenes and tumor angiogenesis: differential modes of vascular endothelial growth factor up-regulation in Ras-transformed epithelial cells and fibroblasts. Cancer Res 60:490-498

Roberts JR, Perkins GD, Fujisawa T, Pettigrew KA, Gao F, Ahmed A, Thickett DR (2007) Vascular endothelial growth factor promotes physical wound repair and is anti-apoptotic in primary distal lung epithelial and A549 cells. Crit Care Med 35:2164-2170

Sato Y, Kanno S, Oda N, Abe M, Ito M, Shitara K, Shibuya M (2000) Properties of two VEGF receptors, Flt-1 and KDR, in signal transduction. Ann N Y Acad Sci 902:201-207

Schrma PS, Sharma R, Tyagi T (2011) VEGF/VEGFR pathway inhibitors as anti-angiogenic agents: present and future. Curr Cancer Drug Targets 11:624-653

Shibuya M (2011) Vascular endothelial growth factor (VEGF) and its receptor (VEGFR) signaling. A crucial target for anti- and proangiogenic therapies. Genes Cancer 2:1097-1105

Singer M, Deutschman CS, Seymour CW, Shankar-Hari M, Annane D, Bauer M, Bellomo R, Bernard GR, Chiche JD, Coopersmith CM, Hotchkiss RS, Levy MM, Marshall JC, Martin GS, Opal SM, Rubenfeld GD, van der Poll T, Vincent JL, Angus DC (2016) The third international consensus definitions for Sepsis and Septic Shock (Sepsis-3). JAMA 315:801-810

Suzuki T, Sakata K, Mizuno N, Palikhe S, Yamashita S, Hattori K, Matsuda N, Hattori Y (2018) Different involvement of the MAPK family in inflammatory regulation in human pulmonary microvascular endothelial cells stimulated with LPS and IFN- $\gamma$. Immunobiology 223:777-785

Taichman NS, Young S, Cruchley AT, Taylor P, Paleolog E (1997) Human neutrophils secrete vascular endothelial growth factor. J Leukoc Biol 62:397-400

Takano K, Yamamoto S, Tomita K, Takashina M, Yokoo H, Matsuda N, Takano Y, Hattori Y (2011) Successful treatment of acute lung injury with pitavastatin in septic mice: potential role of glucocorticoid receptor expression in alveolar macrophages. J Pharmacol Exp Ther 336:381-390

Thickett DR, Armstrong L, Millar AB (2002) A role for vascular endothelial growth factor in acute and resolving lung injury. Am Respir Crit Care Med 166:1332-1337

Tomita K, Takashina M, Mizuno N, Sakata K, Hattori K, Imura J, Ohashi W, Hattori Y (2015) Cardiac fibroblasts: contributory role in septic cardiac dysfunction. J Surg Res 193:874-887

Tsushima K, King LS, Aggarwal NR, De Gorordo A, D'Alessio FR, Kubo K (2009) Acute lung injury review. Intern Med 48:621-630

Unger RE, Krump-Konvalinkova V, Peters K, Kirkpatrick CJ (2002) In vitro expression of the endothelial phenotype: comparative study of primary isolated cells and cell lines, including the novel cell line HPMEC-ST1.6R. Microvasc Res 64:384-397

Villar J, Ribeiro SP, Mullen JB, Kuliszwski M, Post M, Slutsky AS (1994) Induction of the heat shock response reduces mortality rate and organ damage in a sepsis-induced acute lung injury model. Crit Care Med 22:914-921

Yamashita S, Suzuki T, Iguchi K, Sakamoto T, Tomita K, Yokoo H, Sakai M, Misawa H, Hattori K, Nagata T, Watanabe Y, Matsuda N, Yoshimura N, Hattori Y (2018) Cardioprotective and functional effects of levosimendan and milrinone in mice with cecal ligation and puncture-induced sepsis. Naunyn Schmiedeberg's Arch Pharmacol 391:1021-1032

Publisher's note Springer Nature remains neutral with regard to jurisdictional claims in published maps and institutional affiliations. 